Copyright (C) 2021 by Cherkas Global University

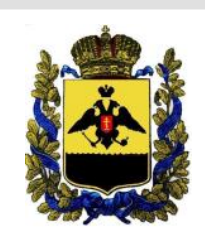

Published in the USA

Bylye Gody

Has been issued since 2006.

E-ISSN: 2310-0028

2021. 16(4): 1789-1799

DOI: $10.13187 /$ bg.2021.4.1789

Journal homepage:

https://bg.cherkasgu.press

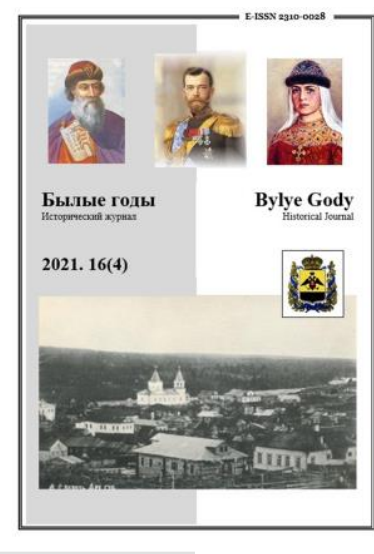

\title{
To the Issue of the Public Education System on the Territory of the Caucasian Educational District in 1848-1917. Part 1
}

\author{
Olga V. Natolochnaya a, b , *, Ruslan M. Allalyev c, d, Alexey V. Dyuzhov d, e, Svetlana V. Petrova ${ }^{\mathrm{f}}$ \\ ${ }^{a}$ Cherkas Global University, Washington, USA \\ b Volgograd State University, Russian Federation \\ ' Peoples' Friendship University of Russia (RUDN University), Moscow, Russian Federation \\ d Plekhanov Russian University of Economics, Russian Federation \\ e Russian State University for the Humanities, Moscow, Russian Federation \\ f Sochi State University, Russian Federation
}

\begin{abstract}
The authors attempt to consider the systems of public education on the territory of the Caucasian Educational District in the period from 1848 to 1917. In this part of the work, the attention is paid to the period from 1848 to 1900 .

There were used as materials the annual "Reports of the trustee of the Caucasian Educational District on the state of educational institutions of the Caucasian Educational District”, which were published from 1884 to 1914 . These reports published data on the public education system subordinated both to the Ministry of Public Education and, especially at the initial stage, on schools of other departments, for example, the Holy Synod.

Due to the specifics of the work, the statistical method was widely used in methodological terms. Thanks to its application, we managed to systematize a variety of statistical information on different types of educational institutions (primary, lower and secondary), as well as to identify changes in the number of students in the Caucasus and pay attention to their gender balance.

The authors come to the conclusion that the system of public education on the territory of the Caucasian Educational District consisted of secondary, lower, primary and private education. Various parish schools (Orthodox, Armenian-Gregorian, Jewish, Muslim) were not subordinated to the Caucasian School District and data on them were not considered in this work. The Caucasian Educational District, created in 1848 , was a territory with scattered centers of public education with the predominance of primary schools. By 1879 there have already been more than 800 educational institutions in the Caucasus, of which 25 are secondary and 32 are lower, together with private ones. By 1900, the number of secondary and lower schools reached 55 and 84, respectively, and the total number of schools reached 1902, with 168 thousand students. Despite the obvious successes in public education, the gender imbalance and the infringement of girls' rights to primary education continued to be a significant problem.
\end{abstract}

Keywords: Caucasian educational district, 1848-1917, public education system, historical and statistical research.

\section{1. Введение}

Кавказ дороссийского периода был одной сплошной территорией геополитических противоречий между разными странами, которые пытались получить ее в качестве сферы своего влияния. Главными претендентами на Кавказ были три империи - Российская, Османская и

\footnotetext{
${ }^{*}$ Corresponding author

E-mail addresses: incfar.natolochnaya@gmail.com (O.V. Natolochnaya) 
Персидская. Две последние видели в этой территории и источник человеческих ресурсов, всячески поощряя межплеменную рознь и покровительствуя работорговле. Понятно, что, когда Россия пришла на Кавказ в самом начале XIX века, он предстал перед русскими чиновниками в высшей степени феодализированным, с полным отсутствием многих государственных институтов. Гражданское общество пришлось создавать, начиная с самых низов, а именно с создания первых начальных школ. С рабозахватчиками и рабовладельцами пришлось воевать на протяжении всей Кавказской войны вплоть до 1864 г. Уже в 1802 г. в Тифлисе было открыто первое двуклассное училище, а в 1829 г., когда было подготовлено значительное количество учащихся с начальным образованием, была открыта и первая на Кавказе Тифлисская гимназия (Shevchenko et al., 2016: 364-366). Еще спустя 19 лет, в 1848 г., император Николай I утвердил положение о Кавказском учебном округе и разрозненные учебные заведения в разных уголках Кавказа обрели систему и были объединены единой сетью. В данной части работы мы хотели бы рассмотреть систему народного образования на Кавказе в период с 1848 по 1900 гг.

\section{2. Материалы и методы}

В качестве материалов были использованы ежегодные «Отчеты попечителя Кавказского учебного округа о состоянии учебных заведений Кавказского учебного округа», которые публиковались с 1884 по 1914 гг. В них публиковались данные о системе народного образования подведомственной как Министерству народного просвещения, так и, в особенности на начальном этапе, о школах других ведомств, например Святейшего синода.

В связи со спецификой работы в методологическом плане широко применялся статистический метод, благодаря которому нам удалось систематизировать разнообразную статистическую информацию по разным типам учебных заведений (начальных, низших и средних), а также выявить изменение количества учащихся на Кавказе и обратить внимание на их гендерный баланс.

\section{3. Обсуждение}

Система дореволюционного народного образования как в масштабах Российской империи, так и Кавказа сегодня активно изучается. Например, анализу системы народного образования на территории украинских губерний посвятил свою работу С.И. Дегтярев (Degtyarev et al., 2020), T.А. Магсумов рассматривал обучение в период Первой русской революции (Magsumov, 2017; Magsumov, 2018), А.А. Овсянникова - общероссийскую систему народного образования империи во второй половине XIX - начале XX вв. (Овсянникова, 2017). В историографии рассматривались и более частные вопросы, например, муниципальной системе народного образования города Москвы в 18851893 гг. уделил внимание К.К. Полещук (Полещук, 2017).

Что касается системы народного образования на Кавказе, то из 15 его регионов изученными считаются около половины - 8. Так, например, А.М. Мамадалиев занимался изучением системы народного образования Тифлисской (Mamadaliev et al., 2020; Mamadaliev et al., 2020a; Mamadaliev et al., 2020b; Mamadaliev et al., 2020c) и Кутаисской губерний (Mamadaliev et al., 2021; Mamadaliev et al., 2021a; Mamadaliev et al., 2021b). T.А. Магсумов обращался к изучению Карской области (Magsumov et al., 2020; Magsumov et al., 2020а) и Бакинской губернии (Magsumov et al., 2021; Magsumov et al., 2021a). В.С. Молчанова рассматривала Кубанскую область (Molchanova et al., 2019; Molchanova et al., 2019a; Molchanova et al., 2020). В сферу научного интереса А.А. Черкасова входили территории Черноморской губернии (Cherkasov et al., 2020; Cherkasov et al., 2020a) и Терской области (Cherkasov et al., 202ob; Cherkasov et al., 2021). О.В. Натолочная обращалась к изучению системы народного образования Ставропольской губернии (Natolochnaya et al., 2020; Natolochnaya et al., 2020a; Natolochnaya et al., 2020b), a К.В. Таран уделил внимание коммерческому образованию на территории Кавказского учебного округа (Taran et al., 2021).

\section{4. Результаты}

Система народного образования в Российской империи делилась на три ступени: начальное, низшее и среднее образование. В рассматриваемое время на Кавказе были представлены все три типа учебных заведений. Как мы отмечали во введении, первая школа была открыта на Кавказе в 1802 г. Затем школы начали появляться в разных регионах, создавались они достаточно тяжелым путем, так как в кавказском обществе начала XIX века не было понимания, для чего образование может пригодиться отпрыскам. Лишь с развитием госучреждений привлечение на государственную службу стало важным стимулом для обучения детей в стенах учебных заведений. Большую роль сыграло и экономическое развитие региона. Когда количество учебных заведений возросло, перед местной администрацией в середине XIX встала новая задача - унифицировать образование под стандарт Российской империи. И это был весьма сложным процессом, так как привычки формировались годами и отказ от них сопровождался сопротивлением. Тем не менее к концу 1870 гг. на Кавказе сложилась целая сеть учебных заведений, которая насчитывала 24 средних учебных заведений, 26 низших и 2100 начальных, включая частные и приходские.

Рассмотрим ступени народного образования по отдельности.

$$
-1790-
$$




\section{Среднее образование}

К средним учебным заведениям в указанное время относились мужские и женские гимназии и прогимназии, реальные училища, учительский институт и учительские семинарии. Систему среднего образования в период с 1879 г. по 1900 г. мы свели в Таблицу 1.

Таблица 1. Средние учебные заведения на Кавказе в 1879-1900 гг. (Памятная книжка, 1879: XIII; Отчет, 1885: 290, 304; Отчет, 1886: 302, 320; Отчет, 1887: 316, 334; Отчет, 1890: табл. 321, 332; Отчет, 1891: табл. 340, 351; Отчет, 1892: табл. 342, 353; Отчет, 1893: 343, 354; Отчет, 1894: 343, 354; Отчет, 1895: 343, 354; Отчет, 1896: 343, 354; Отчет, 1897: 560, 582-583; Отчет, 1899: 534, 556-557; Отчет, 1900: 584, 607; Отчет, 1901: 582, 604-605)

\begin{tabular}{|c|c|c|c|c|c|c|c|c|c|c|c|}
\hline \multirow[t]{3}{*}{ Годы } & \multicolumn{8}{|c|}{ Количество учебных заведений } & \multicolumn{3}{|c|}{ Количество учащихся } \\
\hline & \multicolumn{2}{|c|}{ Гимназий } & \multicolumn{2}{|c|}{ Прогимназий } & \multirow{2}{*}{ 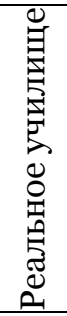 } & \multirow[b]{2}{*}{ 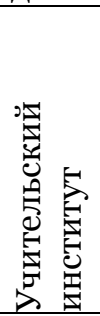 } & \multirow[b]{2}{*}{ 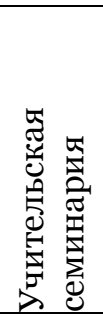 } & \multirow[b]{2}{*}{ 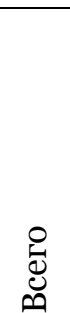 } & \multirow[b]{2}{*}{ 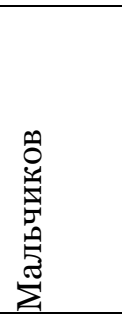 } & \multirow[b]{2}{*}{ 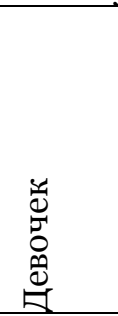 } & \multirow[b]{2}{*}{ 菢 } \\
\hline &  & 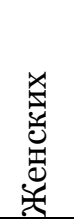 & 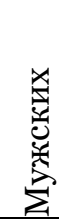 & 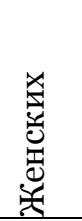 & & & & & & & \\
\hline 1879 & 4 & 5 & 6 & 3 & 3 & 1 & 2 & 24 & 4495 & 2457 & 6952 \\
\hline 1883 & 7 & 7 & 3 & 6 & 8 & 1 & 4 & 36 & 6341 & 3426 & 9767 \\
\hline 1884 & 7 & 7 & 3 & 9 & 8 & 1 & 4 & 39 & 6360 & 3732 & 10092 \\
\hline 1885 & 8 & 8 & 3 & 8 & 8 & 1 & 4 & 40 & 6428 & 3872 & 10300 \\
\hline 1886 & 8 & 8 & 3 & 8 & 8 & 1 & 4 & 40 & 6507 & 4085 & 10592 \\
\hline 1888 & 8 & 9 & 3 & 7 & 8 & 1 & 4 & 40 & 6025 & 4031 & 10056 \\
\hline 1889 & 8 & 9 & 3 & 7 & 8 & 1 & 4 & 40 & 6007 & 4136 & 10143 \\
\hline 1890 & 8 & 9 & 3 & 7 & 8 & 1 & 4 & 40 & 6309 & 4308 & 10617 \\
\hline 1891 & 8 & 9 & 3 & 7 & 8 & 1 & 4 & 40 & 6604 & 4529 & 11133 \\
\hline 1892 & 9 & 10 & 2 & 6 & 8 & 1 & 4 & 40 & 6885 & 4601 & 11486 \\
\hline 1893 & 9 & 10 & 2 & 6 & 8 & 1 & 4 & 40 & 7110 & 4942 & 12052 \\
\hline 1894 & 9 & 11 & 3 & 5 & 8 & 1 & 4 & 41 & 7597 & 5276 & 12873 \\
\hline 1895 & 9 & 11 & 3 & 7 & 8 & 1 & 4 & 43 & 7939 & 5702 & 13641 \\
\hline 1896 & 10 & 11 & 4 & 7 & 8 & 1 & 4 & 45 & 9124 & 6307 & 15460 \\
\hline 1897 & 11 & 13 & 3 & 6 & 9 & 1 & 4 & 46 & Д.н. & Д.н. & 17008 \\
\hline 1898 & 12 & 14 & 2 & 7 & 9 & 1 & 4 & 49 & 10650 & 8151 & 18801 \\
\hline 1899 & 12 & 14 & 2 & 8 & 9 & 1 & 4 & 50 & 11336 & 8697 & 20033 \\
\hline 1900 & 12 & 17 & 1 & 7 & 10 & 1 & 4 & 52 & 11786 & 9627 & 21413 \\
\hline
\end{tabular}

Анализируя Таблицу 1, мы можем видеть, что количество средних учебных заведений за указанное время возросло более чем в 2 раза, а количество обучающихся в 3 раза - с 7 тыс. до 21 тыс. человек. Данные цифры демонстрируют то, что в это время происходило не только увеличение количества учебных заведений, но и числа учащихся, что свидетельствовало, на наш взгляд, о повышающейся востребованности среднего образования в регионе. При этом положительный эффект наблюдался и в гендерном балансе учащихся: если в 1879 г. девочки составляли 35 \% от общего количества учащихся, то в 1900 г. - уже 44,9.

Важной частью образования в средних учебных заведениях было самообразование, и главной роль в нем играли библиотеки. В 1884 г. средние учебные заведения на Кавказе располагали совокупным библиотечным фондом в составе 118 тысяч (118 984) томов, что в среднем составляло по 3 о51 том на учебное заведение (Отчет, 1885: 292). К 1900 г. в библиотечном фонде средних учебных заведений насчитывалось уже 311 тыс. (311 206) томов, что в среднем составляло по 5985 книг на одно среднее учебное заведение (Отчет, 1901: 583). Таким образом, библиотечные фонды возросли почти в 3 раза.

\section{Низшее образование}

К низшим учебным заведениям относились городские и уездные училища, горские и ремесленные школы, а также созданные в 1890-м г. Мариинские женские училища. Данные о низших учебных заведениях мы свели в Таблицу 2. 
Таблица 2. Низшие учебные заведения на Кавказе в 1879-190о гг. (Памятная книжка, 1879: XIII; Отчет, 1885: 290, 304; Отчет, 1886: 302, 320; Отчет, 1887: 316, 334; Отчет, 1890: табл. 321, 332; Отчет, 1891: табл. 340, 351; Отчет, 1892: табл. 342, 353-354; Отчет, 1893: 343, 354; Отчет, 1895: 343, 354; Отчет, 1896: 343, 354; Отчет, 1897: 560, 582; Отчет, 1899: 534, 556; Отчет, 1900: 584, 607; Отчет, 1901: 582, 604)

\begin{tabular}{|c|c|c|c|c|c|c|c|c|}
\hline \multirow[t]{2}{*}{ Годы } & \multicolumn{7}{|c|}{ Количество учебных заведений } & \multirow[t]{2}{*}{ Количество учащихся 1} \\
\hline & 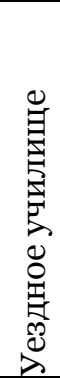 & 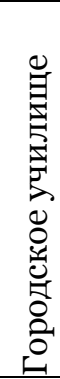 & 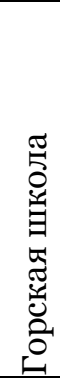 & 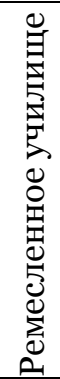 & 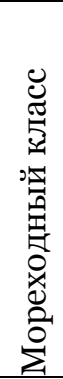 & 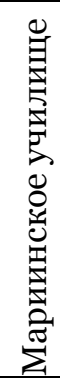 & 它 & \\
\hline 1879 & 6 & 16 & 4 & - & - & - & 26 & 3640 \\
\hline 1883 & 1 & 27 & 5 & 2 & 3 & - & 38 & 5458 \\
\hline 1884 & 1 & 29 & 5 & 3 & 3 & - & 41 & 5990 \\
\hline 1885 & 1 & 29 & 5 & 3 & 3 & - & 41 & 6073 \\
\hline 1886 & 1 & 29 & 5 & 5 & 3 & - & 43 & 6225 \\
\hline 1888 & - & 31 & 5 & 6 & 3 & - & 45 & 6660 \\
\hline 1889 & - & 33 & 5 & 7 & 3 & - & 48 & 7060 \\
\hline 1890 & - & 33 & 5 & 7 & 3 & 2 & 50 & 7667 \\
\hline 1891 & - & 35 & 5 & 7 & 3 & 2 & 52 & 8169 \\
\hline 1892 & - & 36 & 5 & 7 & 3 & 2 & 53 & 8632 \\
\hline 1893 & - & 37 & 5 & 7 & 3 & 2 & 54 & 9086 \\
\hline 1894 & - & 37 & 5 & 7 & 3 & 3 & 54 & 9479 \\
\hline 1895 & - & 37 & 5 & 8 & 3 & 3 & 56 & 9781 \\
\hline 1896 & - & 38 & 5 & 10 & 3 & 3 & 59 & 10809 \\
\hline 1897 & - & 40 & 5 & 14 & 3 & 4 & 66 & 12211 \\
\hline 1898 & - & 42 & 5 & 16 & - & 4 & 67 & 13130 \\
\hline 1899 & - & 42 & 4 & 17 & - & 6 & 69 & 14891 \\
\hline 1900 & - & 45 & 4 & 17 & - & 6 & 72 & 16158 \\
\hline
\end{tabular}

Анализируя Таблицу 2, можно резюмировать, что низшее образование на территории Кавказа так же активно развивалось, как и среднее. Количество учебных заведений увеличилось практически в 3 раза, а число учащихся - в 4,5 раза. При этом если количество городских училищ возросло в 3 раза, то количество ремесленных школ испытало свой по-настоящему золотой век, увеличившись в 9 раз. Помимо этого, уже в 1890 г. на Кавказе появились низшие учебные заведения для девочек ими стали женские Мариинские училища.

Что касается библиотечных фондов, то и здесь было отмечено увеличение фондов для самостоятельного обучения учащихся. Так, 1884 г. низшие учебные заведения на Кавказе располагали библиотечным фондом в составе 59946 томов или по 1462 тома на одно учебное заведение (Отчет, 1885: 292), а уже в 1900 г. в библиотечном фонде низших учебных заведений насчитывалось 177964 тома, что в среднем составляло по 2472 книги на одно низшее учебное заведение (Отчет, 1901: 583). Таким образом, библиотечный фонд вырос в 3 раза.

\section{Начальное образование}

К начальным учебным заведениям относились одно- и двуклассные городские и сельские училища, подчиненные Кавказскому учебному округу. Имеющиеся статистические данные о начальных училищах на территории Кавказа мы свели в Таблицу 3.

\footnotetext{
${ }^{1}$ В числе обучающихся были только мальчики, исключение составляли только Мариинские женские училища. 
Таблица 3. Начальные училища на территории Кавказа в 1879-1900 гг. (Памятная книжка, 1879: XIII; Отчет, 1885: 290, 304; Отчет, 1886: 263; 284, 302, 320; Отчет, 1887: 316, 334; Отчет, 1890: табл. 313, 321; Отчет, 1891: табл. 332, 340, 351; Отчет, 1892: табл. 334, 342, 353; Отчет, 1893: 335, 343; Отчет, 1894: 333, 343; Отчет, 1895: 335, 343, 354; Отчет, 1896: 343, 354; Отчет, 1896: 335, 343, 354; Отчет, 1897: 540, 560, 582; Отчет, 1899: 520-521, 534, 556; Отчет, 1900: 570, 584, 607; Отчет, 1901: 570, $582,604-605)$

\begin{tabular}{|c|c|c|c|c|c|c|}
\hline \multirow[t]{2}{*}{ Годы } & \multicolumn{2}{|c|}{ Училища } & \multirow[t]{2}{*}{ Всего училищ } & \multicolumn{3}{|c|}{ Количество учащихся } \\
\hline & 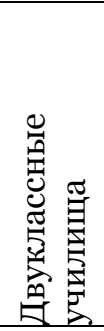 &  & & Мал. & Дев. & Всего \\
\hline 1879 & - & 1768 & $2016^{1}$ & Д. н. & Д. н. & 51267 \\
\hline 1883 & Д. н. & Д. н. & 782 & Д. н. & Д. н. & 40828 \\
\hline 1884 & 89 & 720 & 809 & 33819 & 8432 & 42251 \\
\hline 1885 & 101 & 740 & 841 & 36338 & 9623 & 45961 \\
\hline 1886 & 118 & 805 & 923 & 38811 & 11898 & 50709 \\
\hline 1888 & Д. н. & Д. н. & 876 & Д. н. & Д. н. & 51529 \\
\hline 1889 & 101 & 779 & 880 & 42520 & 10619 & 53139 \\
\hline 1890 & 99 & 794 & 893 & 44929 & 11430 & 56359 \\
\hline 1891 & 105 & 800 & 905 & 46103 & 11672 & 57775 \\
\hline 1892 & 110 & 804 & 914 & 46889 & 12919 & 59758 \\
\hline 1893 & 119 & 798 & 917 & 47522 & 13377 & 60889 \\
\hline 1894 & 127 & 814 & 941 & 50241 & 13951 & 64192 \\
\hline 1895 & 160 & 823 & 983 & 54629 & 16269 & 70898 \\
\hline 1896 & 190 & 871 & 1061 & 61828 & 18033 & 79861 \\
\hline 1897 & Д. н. & Д. н. & 1234 & Д. н. & Д. н. & 89544 \\
\hline 1898 & 258 & 1158 & 1416 & 77856 & 22686 & 100542 \\
\hline 1899 & 264 & 1235 & 1499 & 87035 & 27729 & 114764 \\
\hline 1900 & 283 & 1338 & 1621 & 93445 & 29370 & 122815 \\
\hline
\end{tabular}

В Таблице 3 обращает на себя внимание 1879 г. Дело в том, что в этом году, когда была опубликована «Памятная книжка Кавказского учебного округа», в число учебных заведений были включены все без исключения школы, которые только были в регионе, заканчивая мусульманскими, еврейскими, армяно-григорианскими и церковно-приходскими православными. Ввиду своей специфики конфессиональные школы не включались в состав школ Кавказского учебного округа. Таким образом, реальное же количество школ Кавказского учебного округа в 1879 г. находилось с учетом последующей динамики на уровне не более 700 школ и не более 30 тыс. учащихся. Таким образом, в период с 1879 по 1900 гг. количество начальных учебных заведений возросло с 700 до 1621 , то есть в 2,5 раза. В 4 раза увеличилось количество учащихся с 30 тыс. до 122 тыс. человек. Однако гендерный баланс между девочками и мальчиками на Кавказе в 1883-1900 гг. практически не изменился: в 1883-м г. - девочки составляли 19,9 \% всех учащихся, а в 1900-м г. - 23,9. Что касается качества образования, то уже с начала 1880-х гг. на Кавказе появляются двуклассные начальные учебные заведения и количество их неуклонно росло.

Что касается библиотечного фонда начальных учебных заведений, то в 1884 г. он насчитывал 121236 томов (Отчет, 1885: 292). В 1900 г. в библиотечном фонде начальных учебных заведений насчитывалось - 930684 тома, что в среднем составляло по 574 книги на одну начальную школу (Отчет, 1901: 583). Таким образом, библиотечный фонд увеличился более чем в 7,5 раз.

\section{Частное образование}

Частное образование в Российской империи делилось на разряды: 1-й соответствовал среднему образованию, 2-й - низшему и 3-й - начальному. Данные о частном образовании из ежегодных отчетов попечителя Кавказского учебного округа мы свели в Таблицу 4.

\footnotetext{
${ }^{1}$ В общее количество школ было включено 248 приходских школ всех вероисповеданий. 
Таблица 4. Частные учебные заведения на Кавказе в 1879-190о гг. (Памятная книжка, 1879: XIII; Отчет, 1885: 290, 304; Отчет, 1886: 302, 320; Отчет, 1887: 305, 316, 334; Отчет, 1890: табл. 288, 321; Отчет, 1891: табл. 340, 351; Отчет, 1892: табл. 309, 342, 353; Отчет, 1893: 315, 343; Отчет, 1894: 315, 343; Отчет, 1895: 310, 343, 354; Отчет, 1896: 343, 354; Отчет, 1897: 488, 560, 582; Отчет, 1899: 468, 534, 556; Отчет, 1900: 518, 584, 607; Отчет, 1901: 518, 582, 604)

\begin{tabular}{|c|c|c|c|c|c|}
\hline \multirow[t]{2}{*}{ Годы } & \multicolumn{4}{|c|}{ Количество учебных заведений } & \multirow[t]{2}{*}{ Количество учащихся } \\
\hline & 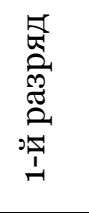 & 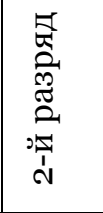 & 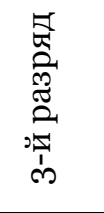 & 苞 & \\
\hline 1879 & 1 & 5 & 4 & 78 & 3210 \\
\hline 1883 & Д. н. & Д. н. & Д. н. & 100 & 3917 \\
\hline 1884 & Д. н. & Д. н. & Д. н. & 97 & 3530 \\
\hline 1885 & 2 & 7 & 87 & 96 & 3785 \\
\hline 1886 & 2 & 6 & 90 & 98 & 3589 \\
\hline 1888 & Д. н. & Д. н. & Д. н. & 104 & 3813 \\
\hline 1889 & 3 & 8 & 87 & 98 & 4011 \\
\hline 1890 & 2 & 7 & 94 & 103 & 3978 \\
\hline 1891 & 3 & 6 & 88 & 96 & 3738 \\
\hline 1892 & 3 & 6 & 80 & 89 & 3807 \\
\hline 1893 & 4 & 6 & 82 & 92 & 4275 \\
\hline 1894 & 4 & 5 & 85 & 94 & 4505 \\
\hline 1895 & 4 & 4 & 91 & 99 & 5351 \\
\hline 1896 & 2 & 8 & 118 & 128 & 6958 \\
\hline 1897 & Д.н. & Д. н. & Д. н. & 139 & 7304 \\
\hline 1898 & 1 & 11 & 125 & 137 & 7286 \\
\hline 1899 & 1 & 10 & 137 & 148 & 7801 \\
\hline 1900 & 3 & 12 & 142 & 157 & 8265 \\
\hline
\end{tabular}

Данные Таблицы 4 показывают, что частное образование на Кавказе не отличалось своей стабильностью. Число средних учебных заведений постоянно колебалось от 1 до 4, аналогичный процесс был и среди низших учебных заведений, хотя, начиная с 1895 г., частные низшие учебные заведения вступили в полосу роста, аналогичный рост показали и частные начальные заведения. Всего в указанный период количество частных учебных заведений увеличилось в 2 раза, а количество учащихся - в 2,5 раза. Таким образом, динамика частных учебных заведений была наиболее слабой среди учебных заведений Кавказского учебного округа. Что касается гендерного состава, то количество девочек в частных учебных заведениях было невелико в 1884 г.: 687, или 21,4 \%, а в 1900 г. -2815 , или $34,3 \%$.

Что касается библиотечного фонда, то информация о нем в частных учебных заведениях в отчетах не публиковалась (Отчет, 1885: 292; Отчет, 1901).

Для обобщения всех приведенных данных из Таблиц 1-4 мы свели все показатели в Таблицу 5, что позволило нам создать целостную картину о системе народного образования на Кавказе в 18791900 гг.

Таблица 5. Сеть учебных заведений на территории Кавказского учебного округа в 1879-1900 гг.

\begin{tabular}{|l|l|l|l|l|l|l|}
\hline \multirow{2}{*}{ Годы } & \multicolumn{5}{|c|}{ Количество учебных заведений } & \multicolumn{2}{l|}{$\begin{array}{l}\text { Количество } \\
\text { учащихся }\end{array}$} \\
\cline { 2 - 7 } & Среднее & Низшее & Начальное & Частное & Всего & \\
\hline 1879 & 24 & 26 & 700 & 78 & 828 & 43802 \\
\hline 1883 & 36 & 38 & 782 & 100 & 956 & 59970 \\
\hline 1884 & 39 & 41 & 809 & 97 & 986 & 61863 \\
\hline 1885 & 40 & 41 & 841 & 96 & 1018 & 66119 \\
\hline 1886 & 40 & 43 & 923 & 98 & 1104 & 71115 \\
\hline 1888 & 40 & 45 & 876 & 104 & 1065 & 72058 \\
\hline 1889 & 40 & 48 & 880 & 98 & 1066 & 74353 \\
\hline 1890 & 40 & 50 & 893 & 103 & 1086 & 78621 \\
\hline
\end{tabular}




\begin{tabular}{|l|l|l|l|l|l|l|}
\hline 1891 & 40 & 52 & 905 & 96 & 1093 & 80815 \\
\hline 1892 & 40 & 53 & 914 & 89 & 1096 & 83683 \\
\hline 1893 & 40 & 54 & 917 & 92 & 1103 & 86302 \\
\hline 1894 & 41 & 54 & 941 & 94 & 1130 & 91049 \\
\hline 1895 & 43 & 56 & 983 & 99 & 1181 & 99671 \\
\hline 1896 & 45 & 59 & 1061 & 128 & 1293 & 113088 \\
\hline 1897 & 46 & 66 & 1234 & 139 & 1485 & 126067 \\
\hline 1898 & 49 & 67 & 1416 & 137 & 1669 & 139939 \\
\hline 1899 & 50 & 69 & 1499 & 148 & 1766 & 157490 \\
\hline 1900 & 52 & 72 & 1621 & 157 & 1902 & 168651 \\
\hline
\end{tabular}

Анализируя Таблицу 5, мы можем видеть резкое увеличение количества учащихся на Кавказе в конце XIX века. Уже в 1895 г. число учащихся практически достигло 100 тыс. человек, а в следующие 5 лет увеличилось еще на 70 \%. В абсолютных цифрах этот рост выразился с 43 тыс. до 168 тыс., или в 3,9 раза, в то время как количество учебных заведений увеличилось только в 2,3 раза. Иными словами, происходило резкое увеличение количества обучающихся на одно учебное заведение. Так, если в 1879 г. на одно учебное заведение приходилось в среднем 53 ученика, то в 1900 г. - уже по 86.

\section{5. Заключение}

Подводя итоги, важно отметить, что система народного образования на территории Кавказского учебного округа состояла из среднего, низшего, начального и частного образования. Различные приходские школы (православные, армяно-григорианские, еврейские, мусульманские) не были подведомственны Кавказскому учебному округу, и сведения о них в данной работе не рассматривались. Созданный в 1848 г. Кавказский учебный округ представлял собой территорию с разрозненными очагами народного образования с превалированием начальных школ. К 1879 г. на Кавказе уже было более 800 учебных заведений, из которых - 25 средних и 32 низших вместе с частными. К 1900 г. количество средних и низших заведений достигло 55 и 84 соответственно, а общее количество школ достигло 1902 при 168 тыс. учащихся.

Несмотря на очевидные успехи в деле народного образования, значительной проблемой продолжал оставаться гендерный дисбаланс и ущемление прав девочек на начальное образование.

\section{Литература}

Овсянникова, 2017 - Овсянникова А.А. Система народного образования Российской империи во второй половине XIX века - начале XX вв. // Социально-политические науки. 2017. № 2. С. 95-99.

Полещук, 2017 - Полещук К.К. Муниципальная система народного образования в Москве при городском голове Н.А. Алексееве в 1885-1893 гг. // Вестник Московского университета. Серия 8 «История». 2017. № 1. С. 54-66.

Отчет, 1885 - Отчет попечителя Кавказского учебного округа о состоянии учебных заведений за 1884 г. Тифлис, 1885.

Отчет, 1886 - Отчет попечителя Кавказского учебного округа о состоянии учебных заведений за 1885 г. Тифлис, 1886.

Отчет, 1887 - Отчет попечителя Кавказского учебного округа о состоянии учебных заведений за 1886 г. Тифлис, 1887.

Отчет, 1890 - Отчет попечителя Кавказского учебного округа о состоянии учебных заведений за 1889 г. Тифлис, 1890.

Отчет, 1891 - Отчет попечителя Кавказского учебного округа о состоянии учебных заведений за 1890 г. Тифлис, 1891.

Отчет, 1892 - Отчет попечителя Кавказского учебного округа о состоянии учебных заведений за 1891 г. Тифлис, 1892.

Отчет, 1893 - Отчет попечителя Кавказского учебного округа о состоянии учебных заведений за 1892 г. Тифлис, 1893.

Отчет, 1894 - Отчет попечителя Кавказского учебного округа о состоянии учебных заведений за 1893 г. Тифлис, 1894.

Отчет, 1895 - Отчет попечителя Кавказского учебного округа о состоянии учебных заведений за 1894 г. Тифлис, 1895.

Отчет, 1896 - Отчет попечителя Кавказского учебного округа о состоянии учебных заведений за 1895 г. Тифлис, 1896.

Отчет, 1897 - Отчет попечителя Кавказского учебного округа о состоянии учебных заведений за 1896 г. Тифлис, 1897.

Отчет, 1899 - Отчет попечителя Кавказского учебного округа о состоянии учебных заведений за 1898 г. Тифлис, 1899. 
Отчет, 1900 - Отчет попечителя Кавказского учебного округа о состоянии учебных заведений за 1899 г. Тифлис, 1900.

Отчет, 1901 - Отчет попечителя Кавказского учебного округа о состоянии учебных заведений за 1900 г. Тифлис, 1901.

Памятная книжка, 1880 - Памятная книжка Кавказского учебного округа на 1879 г. Тифлис, 1879.

Cherkasov et al., 2020 - Cherkasov A.A., Koroleva L.A., Bratanovskii S.N. (2020). The System of Public Education on the Territory of the Black Sea Province in 1896-1917. Part 1 // Vestnik of Saint Petersburg University. History. 65 (3): 750-770.

Cherkasov et al., 2020a - Cherkasov A.A., Koroleva L.A., Bratanovskii S.N. (2020). The System of Public Education on the Territory of the Black Sea Province in 1896-1917. Part 2 // Vestnik of Saint Petersburg University. History. 65 (4): 1067-1084.

Cherkasov et al., 2020b - Cherkasov A.A., Bratanovskii S.N., Zimovets L.G. (2020). The System of Public Education in Terek Oblast in the Period 1860-1917. Part 1 // European Journal of Contemporary Education. 9(4): 963-970.

Cherkasov et al., 2021 - Cherkasov A.A., Bratanovskii S.N., Zimovets L.G. (2021). The System of Public Education in Terek Oblast in the Period 1860-1917. Part 2// European Journal of Contemporary Education. 10(1): 211-218.

Degtyarev et al., 2020 - Degtyarev S.I., Polyakova L.G., Gut J. (2020). The Social Background of Functionaries in the Russian Empire's Public Education Sector in the First Half of the 19th century: The Case of the Ukrainian Governorates // European Journal of Contemporary Education. 9(1): 212-220.

Magsumov et al., 2020 - Magsumov T.A., Korolev A.A., Ponomareva M.A., Zulfugarzade T.E. (2020). The System of Public Education in Kars Oblast in the Period 1878-1917. Part 1 // European Journal of Contemporary Education. 9(1): 221-234.

Magsumov et al., 2020a - Magsumov T.A., Korolev A.A., Ponomareva M.A., Zulfugarzade T.E. (2020). The System of Public Education in Kars Oblast in the Period 1878-1917. Part 2 // European Journal of Contemporary Education. 9(2): 459-472.

Magsumov et al., 2021 - Magsumov T.A., Zulfugarzade T.E., Kolotkov M.B., Zinkovskii S.B. (2021). The System of Public Education in Baku Governorate in the Period between the second half of the 19th century and the early 2oth century. Part 1 // European Journal of Contemporary Education. 10(2): 529-545.

Magsumov et al., 2021a - Magsumov T.A., Zulfugarzade T.E., Kolotkov M.B., Zinkovskii S.B. (2021).

The System of Public Education in Baku Governorate in the Period between the Second Half of the 19th Century and the Early 2oth Century. Part 2 // European Journal of Contemporary Education. 10(3): 822-836.

Magsumov, 2017 - Magsumov, T.A. Family and school in Russia at the beginning of the 2oth century: Attempts to bridge the gap // European Journal of Contemporary Education. 2017. 6(4): 837-846.

Magsumov, 2018 - Magsumov T.A. (2018). Vocational school and studying youth in the Russian revolution of 1905 // Terra Sebus. 10: 289-313.

Mamadaliev et al., 2020 - Mamadaliev A.M., Karpukhin D.V., Svechnikova N.V., Médico A. (2020). The System of Public Education in Tiflis Governorate in the Period 1802-1917. Part 1 // European Journal of Contemporary Education. 9(1): 235-247.

Mamadaliev et al., 2020a - Mamadaliev A.M., Karpukhin D.V., Svechnikova N.V., Médico A. (2020). The System of Public Education in Tiflis Governorate in the Period 1802-1917. Part 2 // Bylye Gody. 56(2): 530-540.

Mamadaliev et al., 2020b - Mamadaliev A.M., Karpukhin D.V., Svechnikova N.V., Médico A. (2020). The System of Public Education in Tiflis Governorate in the Period 1802-1917. Part 3 // Bylye Gody. 57(3): 1065-1084.

Mamadaliev et al., 2020c - Mamadaliev A.M., Karpukhin D.V., Svechnikova N.V., Médico A. (2020). The System of Public Education in Tiflis Governorate in the Period 1802-1917. Part 4 // Bylye Gody. 58(4): 2409-2426.

Mamadaliev et al., 2021 - Mamadaliev A.M., Karpukhin D.V., Svechnikova N.V., Médico A. (2021). The System of Public Education in the Kutaisi Province in 1846-1917. Part 1 // Bylye Gody. 16(1): 169-181.

Mamadaliev et al., 2021a - Mamadaliev A.M., Karpukhin D.V., Svechnikova N.V., Koroleva L.A. (2021). The System of Public Education in the Kutaisi Province in 1846-1917. Part 2 // Bylye Gody. 16(2): 699-716.

Mamadaliev et al., 2021b - Mamadaliev A.M., Novitskaya L.Yu., Svechnikova N.V., Koroleva L.A. (2021).

The System of Public Education in the Kutaisi Province in 1846-1917. Part 3 // Bylye Gody. 16(3): 1191-1202.

Molchanova et al., 2019 - Molchanova V.S., Balanyuk L.L., Vidishcheva E.V., Potapova I.I. (2019).

The Development of Primary Education on the Cossack Territories in 1803-1917 years (on the Example of the Kuban Region). Part 1 // Bylye Gody. 53(3): 1049-1058.

Molchanova et al., 2019a - Molchanova V.S., Balanyuk L.L., Vidishcheva E.V., Potapova I.I. (2019). The Development of Primary Education on the Cossack Territories in 1803-1917 years (on the Example of the Kuban Region). Part 2 // Bylye Gody. 54(4): 1524-1536.

Molchanova et al., 2020 - Molchanova V.S., Balanyuk L.L., Vidishcheva E.V., Potapova I.I. (2020). The Development of Primary Education on the Cossack Territories in 1803-1917 years (on the Example of the Kuban Region). Part 3 // Bylye Gody. 55(1): 88-104. 
Natolochnaya et al., 2020 - Natolochnaya O.V., Zimovets L.G., Allalyev R.M., Svechnikov V.A. (2020). The System of Public Education in Stavropol Governorate in the Period 1804-1917. Part 1 // European Journal of Contemporary Education. 9(2): 473-480.

Natolochnaya et al., 2020a - Natolochnaya O.V., Makarov Y.N., Allalyev R.M., Svechnikov V.A. (2020). The System of Public Education in Stavropol Governorate in the Period 1804-1917. Part 2 // European Journal of Contemporary Education. 9(3): 679-688.

Natolochnaya et al., 2020b - Natolochnaya O.V., Allalyev R.M., Svechnikov V.A., Ivantsov V.G. (2020). The System of Public Education in Stavropol Governorate in the Period 1804-1917. Part 3 // European Journal of Contemporary Education. 9(4): 984-992.

Shevchenko et al., 2016 - Shevchenko N.A., Vidishcheva E.V., Emelyanova O.V. (2016). The establishment of the system of public education in the Caucasus (1802-1917 years): The characteristic features // Bylye Gody. 40(2): 363-372.

Taran et al., 2021 - Taran K.V., Korolev A.A., Ludwig S.D., Pestereva N.M. (2021). Private Educational Institutions in the Caucasus in the Period 1846-1914: A Historical-Statistical Study // European Journal of Contemporary Education. 10(3): 812-821.

\section{References}

Cherkasov et al., 2020 - Cherkasov, A.A., Koroleva, L.A., Bratanovskii, S.N. (2020). The System of Public Education on the Territory of the Black Sea Province in 1896-1917. Part 1. Vestnik of Saint Petersburg University. History. 65 (3): 750-770.

Cherkasov et al., 2020a - Cherkasov, A.A., Koroleva, L.A., Bratanovskii, S.N. (2020). The System of Public Education on the Territory of the Black Sea Province in 1896-1917. Part 2. Vestnik of Saint Petersburg University. History. 65 (4): 1067-1084.

Cherkasov et al., 2020b - Cherkasov, A.A., Bratanovskii, S.N., Zimovets, L.G. (2020). The System of Public Education in Terek Oblast in the Period 1860-1917. Part 1. European Journal of Contemporary Education. 9(4): 963-970.

Cherkasov et al., 2021 - Cherkasov A.A., Bratanovskii S.N., Zimovets L.G. (2021). The System of Public Education in Terek Oblast in the Period 1860-1917. Part 2. European Journal of Contemporary Education. 10(1): 211-218.

Degtyarev et al., 2020 - Degtyarev, S.I., Polyakova, L.G., Gut, J. (2020). The Social Background of Functionaries in the Russian Empire's Public Education Sector in the First Half of the 19th century: The Case of the Ukrainian Governorates. European Journal of Contemporary Education. 9(1): 212-220.

Magsumov et al., 2020 - Magsumov, T.A., Korolev, A.A., Ponomareva, M.A., Zulfugarzade, T.E. (2020). The System of Public Education in Kars Oblast in the Period 1878-1917. Part 1. European Journal of Contemporary Education. 9(1): 221-234.

Magsumov et al., 2020a - Magsumov, T.A., Korolev, A.A., Ponomareva, M.A., Zulfugarzade, T.E. (2020). The System of Public Education in Kars Oblast in the Period 1878-1917. Part 2. European Journal of Contemporary Education. 9(2): 459-472.

Magsumov et al., 2021 - Magsumov, T.A., Zulfugarzade, T.E., Kolotkov, M.B., Zinkovskii, S.B. (2021). The System of Public Education in Baku Governorate in the Period between the second half of the 19th century and the early 2oth century. Part 1. European Journal of Contemporary Education. 10(2): 529-545.

Magsumov et al., 2021a - Magsumov, T.A., Zulfugarzade, T.E., Kolotkov, M.B., Zinkovskii, S.B. (2021). The System of Public Education in Baku Governorate in the Period between the Second Half of the 19th Century and the Early 2oth Century. Part 2. European Journal of Contemporary Education. 10(3): 822-836.

Magsumov, 2017 - Magsumov, T.A. (2017). Family and school in Russia at the beginning of the 2oth century: Attempts to bridge the gap. European Journal of Contemporary Education. 6(4): 837-846.

Magsumov, 2018 - Magsumov, T.A. (2018). Vocational school and studying youth in the Russian revolution of 1905. Terra Sebus. 10: 289-313.

Mamadaliev et al., 2020 - Mamadaliev, A.M., Karpukhin, D.V., Svechnikova, N.V., Médico, A. (2020). The System of Public Education in Tiflis Governorate in the Period 1802-1917. Part 1. European Journal of Contemporary Education. 9(1): 235-247.

Mamadaliev et al., 2020a - Mamadaliev, A.M., Karpukhin, D.V., Svechnikova, N.V., Médico, A. (2020). The System of Public Education in Tiflis Governorate in the Period 1802-1917. Part 2. Bylye Gody. 56(2): 530-540.

Mamadaliev et al., 2020b - Mamadaliev, A.M., Karpukhin, D.V., Svechnikova, N.V., Médico, A. (2020). The System of Public Education in Tiflis Governorate in the Period 1802-1917. Part 3. Bylye Gody. 57(3): 1065-1084.

Mamadaliev et al., 2020c - Mamadaliev, A.M., Karpukhin, D.V., Svechnikova, N.V., Médico, A. (2020). The System of Public Education in Tiflis Governorate in the Period 1802-1917. Part 4. Bylye Gody. 58(4): 2409-2426.

Mamadaliev et al., 2021 - Mamadaliev, A.M., Karpukhin, D.V., Svechnikova, N.V., Médico, A. (2021). The System of Public Education in the Kutaisi Province in 1846-1917. Part 1. Bylye Gody. 16(1): 169-181. 
Mamadaliev et al., 2021a - Mamadaliev, A.M., Karpukhin, D.V., Svechnikova, N.V., Koroleva, L.A. (2021). The System of Public Education in the Kutaisi Province in 1846-1917. Part 2. Bylye Gody. 16(2): 699-716.

Mamadaliev et al., 2021b - Mamadaliev, A.M., Novitskaya, L.Yu., Svechnikova, N.V., Koroleva, L.A. (2021). The System of Public Education in the Kutaisi Province in 1846-1917. Part 3. Bylye Gody. 16(3): 1191-1202.

Molchanova et al., 2019 - Molchanova, V.S., Balanyuk, L.L., Vidishcheva, E.V., Potapova, I.I. (2019). The Development of Primary Education on the Cossack Territories in 1803-1917 years (on the Example of the Kuban Region). Part 1. Bylye Gody. 53(3): 1049-1058.

Molchanova et al., 2019a - Molchanova, V.S., Balanyuk, L.L., Vidishcheva, E.V., Potapova, I.I. (2019). The Development of Primary Education on the Cossack Territories in 1803-1917 years (on the Example of the Kuban Region). Part 2. Bylye Gody. 54(4): 1524-1536.

Molchanova et al., 2020 - Molchanova, V.S., Balanyuk, L.L., Vidishcheva, E.V., Potapova, I.I. (2020). The Development of Primary Education on the Cossack Territories in 1803-1917 years (on the Example of the Kuban Region). Part 3. Bylye Gody. 55(1): 88-104.

Natolochnaya et al., 2020 - Natolochnaya, O.V., Zimovets, L.G., Allalyev, R.M., Svechnikov, V.A. (2020). The System of Public Education in Stavropol Governorate in the Period 1804-1917. Part 1. European Journal of Contemporary Education. 9(2): 473-480.

Natolochnaya et al., 2020a - Natolochnaya, O.V., Makarov, Y.N., Allalyev, R.M., Svechnikov, V.A. (2020). The System of Public Education in Stavropol Governorate in the Period 1804-1917. Part 2. European Journal of Contemporary Education. 9(3): 679-688.

Natolochnaya et al., 2020b - Natolochnaya, O.V., Allalyev, R.M., Svechnikov, V.A., Ivantsov, V.G. (2020). The System of Public Education in Stavropol Governorate in the Period 1804-1917. Part 3. European Journal of Contemporary Education. 9(4): 984-992.

Otchet, 1885 - Otchet popechitelya Kavkazskogo uchebnogo okruga o sostoyanii uchebnykh zavedenii za $1884 \mathrm{~g}$. [Report of the trustee of the Caucasian educational district on the state of educational institutions for 1884]. Tiflis, 1885. [in Russian]

Otchet, 1886 - Otchet popechitelya Kavkazskogo uchebnogo okruga o sostoyanii uchebnykh zavedenii za $1885 \mathrm{~g}$. [Report of the trustee of the Caucasian educational district on the state of educational institutions for 1885]. Tiflis, 1886. [in Russian]

Otchet, 1887 - Otchet popechitelya Kavkazskogo uchebnogo okruga o sostoyanii uchebnykh zavedenii za $1886 \mathrm{~g}$. [Report of the trustee of the Caucasian educational district on the state of educational institutions for 1886]. Tiflis, 1887. [in Russian]

Otchet, 1890 - Otchet popechitelya Kavkazskogo uchebnogo okruga o sostoyanii uchebnykh zavedenii za $1889 \mathrm{~g}$. [Report of the trustee of the Caucasian educational district on the state of educational institutions for 1889]. Tiflis, 1890. [in Russian]

Otchet, 1891 - Otchet popechitelya Kavkazskogo uchebnogo okruga o sostoyanii uchebnykh zavedenii za 1890 g. [Report of the trustee of the Caucasian educational district on the state of educational institutions for 1890]. Tiflis, 1891. [in Russian]

Otchet, 1892 - Otchet popechitelya Kavkazskogo uchebnogo okruga o sostoyanii uchebnykh zavedenii za $1891 \mathrm{~g}$. [Report of the trustee of the Caucasian educational district on the state of educational institutions for 1891]. Tiflis, 1892. [in Russian]

Otchet, 1893 - Otchet popechitelya Kavkazskogo uchebnogo okruga o sostoyanii uchebnykh zavedenii za $1892 \mathrm{~g}$. [Report of the trustee of the Caucasian educational district on the state of educational institutions for 1892]. Tiflis, 1893. [in Russian]

Otchet, 1894 - Otchet popechitelya Kavkazskogo uchebnogo okruga o sostoyanii uchebnykh zavedenii za $1893 \mathrm{~g}$. [Report of the trustee of the Caucasian educational district on the state of educational institutions for 1893]. Tiflis, 1894. [in Russian]

Otchet, 1895 - Otchet popechitelya Kavkazskogo uchebnogo okruga o sostoyanii uchebnykh zavedenii za $1894 \mathrm{~g}$. [Report of the trustee of the Caucasian educational district on the state of educational institutions for 1894]. Tiflis, 1895. [in Russian]

Otchet, 1896 - Otchet popechitelya Kavkazskogo uchebnogo okruga o sostoyanii uchebnykh zavedenii za $1895 \mathrm{~g}$. [Report of the trustee of the Caucasian educational district on the state of educational institutions for 1895]. Tiflis, 1896. [in Russian]

Otchet, 1897 - Otchet popechitelya Kavkazskogo uchebnogo okruga o sostoyanii uchebnykh zavedenii za $1896 \mathrm{~g}$. [Report of the trustee of the Caucasian educational district on the state of educational institutions for 1896]. Tiflis, 1897. [in Russian]

Otchet, 1899 - Otchet popechitelya Kavkazskogo uchebnogo okruga o sostoyanii uchebnykh zavedenii za $1898 \mathrm{~g}$. [Report of the trustee of the Caucasian educational district on the state of educational institutions for 1898]. Tiflis, 1899. [in Russian]

Otchet, 1900 - Otchet popechitelya Kavkazskogo uchebnogo okruga o sostoyanii uchebnykh zavedenii za 1899 g. [Report on the status of educational institutions of the Caucasian educational district in 1899]. Tiflis, 1900. [in Russian] 
Otchet, 1901 - Otchet popechitelya Kavkazskogo uchebnogo okruga o sostoyanii uchebnykh zavedenii za 1900 g. [Report on the status of educational institutions of the Caucasian educational district in 1900]. Tiflis, 1901. [in Russian]

Ovsyannikova, 2017 - Ovsyannikova, A.A. (2017). Sistema narodnogo obrazovaniya Rossiiskoi imperii vo vtoroi polovine XIX veka - nachale XX vv. [The system of public education of the Russian Empire in the second half of the XIX century - the beginning of the XX centuries]. Sotsial'no-politicheskie nauki. 2: 95-99. [in Russian]

Pamyatnaya knizhka, 1880 - Pamyatnaya knizhka Kavkazskogo uchebnogo okruga na 1879 g. [Commemorative book of the Caucasian educational district for 1879.]. Tiflis, 1879. [in Russian]

Poleshchuk, 2017 - Poleshchuk, K.K. (2017). Munitsipal'naya sistema narodnogo obrazovaniya v Moskve pri gorodskom golove N.A. Alekseeve v $1885-1893$ gg. [The municipal system of public education in Moscow under the mayor N.A. Alekseev in 1885 - 1893]. Vestnik Moskovskogo universiteta. Seriya 8: Istoriya. 1: 54-66. [in Russian]

Shevchenko et al., 2016 - Shevchenko, N.A., Vidishcheva, E.V., Emelyanova, O.V. (2016). The establishment of the system of public education in the Caucasus (1802-1917 years): The characteristic features. Bylye Gody. 40(2): 363-372.

Taran et al., 2021 - Taran, K.V., Korolev, A.A., Ludwig, S.D., Pestereva, N.M. (2021). Private Educational Institutions in the Caucasus in the Period 1846-1914: A Historical-Statistical Study. European Journal of Contemporary Education. 10(3): 812-821.

\section{К вопросу о системе народного образования на территории Кавказского учебного округа в 1848-1917 гг. Часть 1}

Ольга Васильевна Натолочная a , b , , Руслан Мурадович Аллалыев ${ }^{\mathrm{c}, \mathrm{d}}$, Алексей Владимирович Дюжов ${ }^{\mathrm{d}, \mathrm{e}}$, Светлана Владиславовна Петрова ${ }^{\mathrm{f}}$

а Черкас глобальный университет, Вашингтон, США

b Волгоградский государственный университет, Волгоград, Российская Федерация

с Российский университет дружбы народов, Москва, Российская Федерация

$\mathrm{d}$ Российский экономический университет им Г.В. Плеханова, Москва, Российская Федерация

е Российский государственный гуманитарный университет, Москва, Российская Федерация

${ }_{\mathrm{f}}$ Сочинский государственный университет, Сочи, Российская Федерация

Аннотация. В работе делается попытка рассмотреть системы народного образования на территории Кавказского учебного округа в период с 1848 по 1917 гг. В данной части работы уделяется внимание периоду с 1848 по 1900 гг.

В качестве материалов были использованы ежегодные «Отчеты попечителя Кавказского учебного округа о состоянии учебных заведений Кавказского учебного округа», которые публиковались с 1884 по 1914 гг. В них публиковались данные о системе народного образования подведомственной как Министерству народного просвещения, так и (в особенности на начальном этапе) другим ведомствам, например Святейшему синоду.

В связи со спецификой работы в методологическом плане широко применялся статистический метод. Благодаря ему, нам удалось систематизировать разнообразную статистическую информацию по разным типам учебных заведений (начальных, низших и средних), а также выявить изменение количества учащихся на Кавказе и обратить внимание на их гендерный баланс.

В заключении авторы приходят к выводу, что система народного образования на территории Кавказского учебного округа состояла из среднего, низшего, начального и частного образования. Различные приходские школы (православные, армяно-григорианские, еврейские, мусульманские) не были подведомственны Кавказскому учебному округу, и сведения о них в данной работе не рассматривались. Созданный в 1848 г. Кавказский учебный округ представлял собой территорию с разрозненными очагами народного образования с превалированием начальных школ. К 1879 г. на Кавказе уже было более 800 учебных заведений, из которых - 25 средних и 32 низших вместе с частными. К 1900 г. количество средних и низших заведений достигло 55 и 84 соответственно, а общее количество школ достигло 1902 при 168 тыс. учащихся. Несмотря на очевидные успехи в деле народного образования, значительной проблемой продолжал оставаться гендерный дисбаланс и ущемление прав девочек на начальное образование.

Ключевые слова: Кавказский учебный округ, 1848-1917 гг., система народного образования, историко-статистическое исследование.

\footnotetext{
${ }^{*}$ Корреспондирующий автор

Адреса электронной почты: incfar.natolochnaya@gmail.com (О.В. Натолочная) 